\title{
Time-motion analysis on Chinese male field hockey players
}

\author{
Hongyou Liu ${ }^{1,2}$, Gang Zhao², Miguel A. Gómez ${ }^{1}$, Javier S. Molinuevo ${ }^{1}$, Jesús V. \\ Giménez ${ }^{1}$, Hui Kang ${ }^{2}$ \\ ${ }^{1}$ Faculty of Physical Activity and Sport Sciences, Polytechnic University of Madrid, Madrid, Spain, \\ ${ }^{2}$ Sport Department, Shenzhen University, Shenzhen, China
}

\begin{abstract}
The aim of the study was to evaluate the match work-rate of Chinese field hockey players by analyzing the distance covered at different intensities pooled by specific positions during different periods of matches. Thirty-eight players from twenty-four male field hockey matches at the $11^{\text {th }}$ Chinese National Games were filmed and analyzed. Results showed that players covered an average distance of $7334 \pm 877 \mathrm{~m}$; 91.7\% of this distance was covered at low and medium intensity; total distance covered in the first half $(3693 \pm 441 \mathrm{~m})$ was more $(p<0.001)$ than the second $(3640 \pm 437 \mathrm{~m})$; distance covered at all speed zones (except walking) significantly decreased at the second half; total distance covered by forwards $(7709 \pm 720 \mathrm{~m})$ and midfielders $(7733 \pm 729 \mathrm{~m})$ was greater than defenders ( $6671 \pm 745 \mathrm{~m})$; positional difference were detected among all the speed zones as well; comparison of interaction of the match period and playing position showed higher values in sprinting during the first half compared to the second for forwards $(p<0.01)$, and in moderate-speed running for defenders $(p=0.0001)$. These results could be used to provide guidance on evaluating players' performance and formulating training prescriptions.
\end{abstract}

Keywords: Activity profile, time-motion analysis, physiological demands, performance analysis, field hockey.

\section{Introduction}

It is well demonstrated that the most effective training methods for athletes preparing for competition is that which most closely stimulates the work intensity of competitive performance conditions in field-based team games, including football, handball, basketball, rugby and hockey (Di Salvo et al., 2007; Gabbett, 2010). Therefore, it is of great importance to scientifically and accurately evaluate the players' match work-rate 
profiles. According to Reilly (2001), "work-rate profiles of players within a field-game-team can be established according to the intensity, duration, and frequency of classified activities, which can be observed by means of motion analysis." Since the early 1970s, a lot of studies have been carried out to investigate the distance and duration of match movement patterns which are commonly called time-motion analysis. Particularly, the available literature is large in analysis of football (Reilly and Thomas, 1976; Mayhew and Wenger, 1985; Bangsbo et al., 1991; Castagna et al., 2003; Stroyer et al., 2004; Barros et al., 2007; Di Salvo et al., 2007); however, in the team sport of field hockey, the research is quite scarce.

Due to the popularity of field hockey and its status as an Olympic sport (Podgórski and Pawlak, 2011), nowadays, there is an increasing number of studies focus on field hockey. Boddington et al. (2002) employed a video analysis to quantify the horizontal displacement of club-level female field hockey players in order to determine their match physical demands. Result of this research showed that players' mean total displacement was $3904 \pm 552 \mathrm{~m}, 97.4 \%$ of them were at low intensity (standing, walking and jogging). However, this research is always criticized because the players' positions were only recorded every $15 \mathrm{~s}$ in the video.

Spencer et al. (2004) introduced the software Labview to analyze the video of an international field hockey match to document the players' movement patterns, with especial attention to the repeated-sprint activities. It was reported that standing, walking and jogging accounted for approximately $95 \%$ of the player's match time. Macleod et al. (2007) used the software of Focus $X 2$ to analyze match videos of twelve players from the women's English National League, which found that players spent $92.1 \pm 7.4 \%$ match time in low intensity activity, and high intensity activity showed a significant decrease at the second half of match, while low-intensity activity of two halves showed no significance. They found that only one positional variation occurred: defenders spending significantly less time walking than forwards. However, as the distance covered by players was not analyzed in neither of the above two studies, the moving velocity could not be calculated to define the intensity. They adapted the same intensity categories (standing, walking, jogging, striding and sprinting) that were defined by video (Spencer et al., 2004), which was not fully convinced.

Gabbett (2010) compared the physiological demands of 14 elite Australian female field hockey players during 19 training and 32 league competitions using GPS technology. Results showed that the average distance covered by players was $6.6 \mathrm{~km}, 97.3 \%$ of match time was spent in low $\left(0-1 \mathrm{~m} \cdot \mathrm{s}^{-1}\right)$ to moderate $\left(1-3 \mathrm{~m} \cdot \mathrm{s}^{-1} ; 3-5 \mathrm{~m} \cdot \mathrm{s}^{-1}\right)$ intensity activities, and strikers covered $92.4 \%$ of the total distance at low $\left(0-1 \mathrm{~m} \cdot \mathrm{s}^{-1}\right) \&$ moderate $\left(1-3 \mathrm{~m} \cdot \mathrm{s}^{-1} ; 3-5 \mathrm{~m} \cdot \mathrm{s}^{-1}\right)$ intensity and $7.7 \%$ at $\operatorname{high}\left(5-7 \mathrm{~m} \cdot \mathrm{s}^{-1} ;>7 \mathrm{~m} \cdot \mathrm{s}^{-1}\right)$ intensity, midfielders $90.7 \%$ and $9.3 \%$, defenders $93.7 \%$ and $6.3 \%$, respectively. On the other hand, Macutkiewicz and Sunderland (2011) studied 25 elite female field hockey players which also used GPS technology and demonstrated that elite women hockey players 
covered a mean distance of $5541 \pm 1144 \mathrm{~m}$ in $48 \pm 4 \mathrm{~min}$ match time. The distance covered by high-intensity running (15.1-19.0 $\left.\mathrm{km} \cdot \mathrm{h}^{-1}\right)$ and sprinting $\left(>19.0 \mathrm{~km} \cdot \mathrm{h}^{-1}\right)$ was $853 \pm 237 \mathrm{~m}$ and $232 \pm 96 \mathrm{~m}$ respectively. Forwards spent a greater percentage of time running (11.1-15.0 $\left.\mathrm{km} \cdot \mathrm{h}^{-1}\right)$, fast running (15.1-19.0 $\left.\mathrm{km} \cdot \mathrm{h}^{-1}\right)$, and sprinting $\left(>19.0 \mathrm{~km} \cdot \mathrm{h}^{-1}\right)$ than midfielders and defenders. The difference between two halves was not compared in either study.

Lythe and Kilding (2011) found that in elite male hockey matches mean distance covered by individual player was $6798 \pm 2009 \mathrm{~m}$; distance covered per position was $8160 \pm 428 \mathrm{~m}$; and high-intensity running $\left(>19.0 \mathrm{~km} \cdot \mathrm{h}^{-1}\right)$ comprised $6.1 \%(479 \pm 108)$ of total distance covered. They also detected that there was a significant decrease of mean total distance covered by the first half to the second and a decrease in the speed zone of $6.1-11 \mathrm{~km} \cdot \mathrm{h}^{-1}$. Recently, Jennings et al.(2012) found that at the 2009 Champions Trophy, strikers covered $22.3 \%$ high-speed-running $\left(>4.17 \mathrm{~m} \cdot \mathrm{s}^{-1}\right)$ distance $(2189 \mathrm{~m})$ out of total (9819 m), midfielders 25.1\% (2554/10160) and defenders 18.3\% (1734/9453).

One particularity of field hockey is that the rules allow unlimited substitutions of players during matches (Jennings et al., 2012), which leads to a reduced number of players who play full matches. In this regard, previous research either chose to analyze the performance profiles of individual player who played part of a match or chose to analyze per position of whole match which played by different players (Jennings et al., 2012; Lythe and Kilding, 2011; Macutkiewicz and Sunderland, 2011). This fact would have generated an imbalanced sample which could affect the evaluation of match activity profiles of players and consequently affect the assessment of field hockey players' match work-rate.

Taking into account the specific framework previously mentioned, the aim of the present study was to evaluate the match work-rate of individualized Chinese field hockey players who played the $70 \mathrm{~min}$ of matches in the same position by analyzing the distance covered at different intensities (i.e., sprint, high speed running, moderate-speed running, low-speed running, jogging and walking) pooled by specific positions in match. It was hypothesized that individual player's match performance in field hockey is differed by the playing position and also by the match period (i.e., first and second half).

\section{Methods}

\subsection{Video filming}

There are no professional field hockey leagues in China; therefore the matches at the tournament of Chinese National Games represent the highest competition level of Chinese field hockey. All the male field hockey matches of the 11th Chinese National Games held in Shandong were recorded. Filming was performed using tow digital cameras (Sony DCR-TRV 11E) positioned at the highest standing of each half of the 
pitch. Each camera recorded one half of the pitch, so that all the match activities could be filmed. The tow cameras were in the same height, and their position and focal distance remained unchanged during the whole filming. Institutional ethics committee approval was obtained before the video filming.

\subsection{Data Collection}

All the videos filmed were transferred into personal computers and were then dealt to be synchronized and transferred into the software of SIMI Scout (Unterschleissheim, Germany) to be further analyzed.

In the system of SIMI Scout, each half of the pitch in the videos could be calibrated in a two-dimensional coordinate according to the pitch size (See Figure 1); therefore any position of the pitch has a corresponding coordinate (X, Y). A click at the player could generate the time of the video (hh:mm:ss) and the coordinate of his position. In this way, all the players could be trailed and located in the video. All the data of time and coordinates could be extracted and transferred into an Excel file. The video was played at a normal frame frequency $(2 \mathrm{~Hz})$ and could be paused at any time.

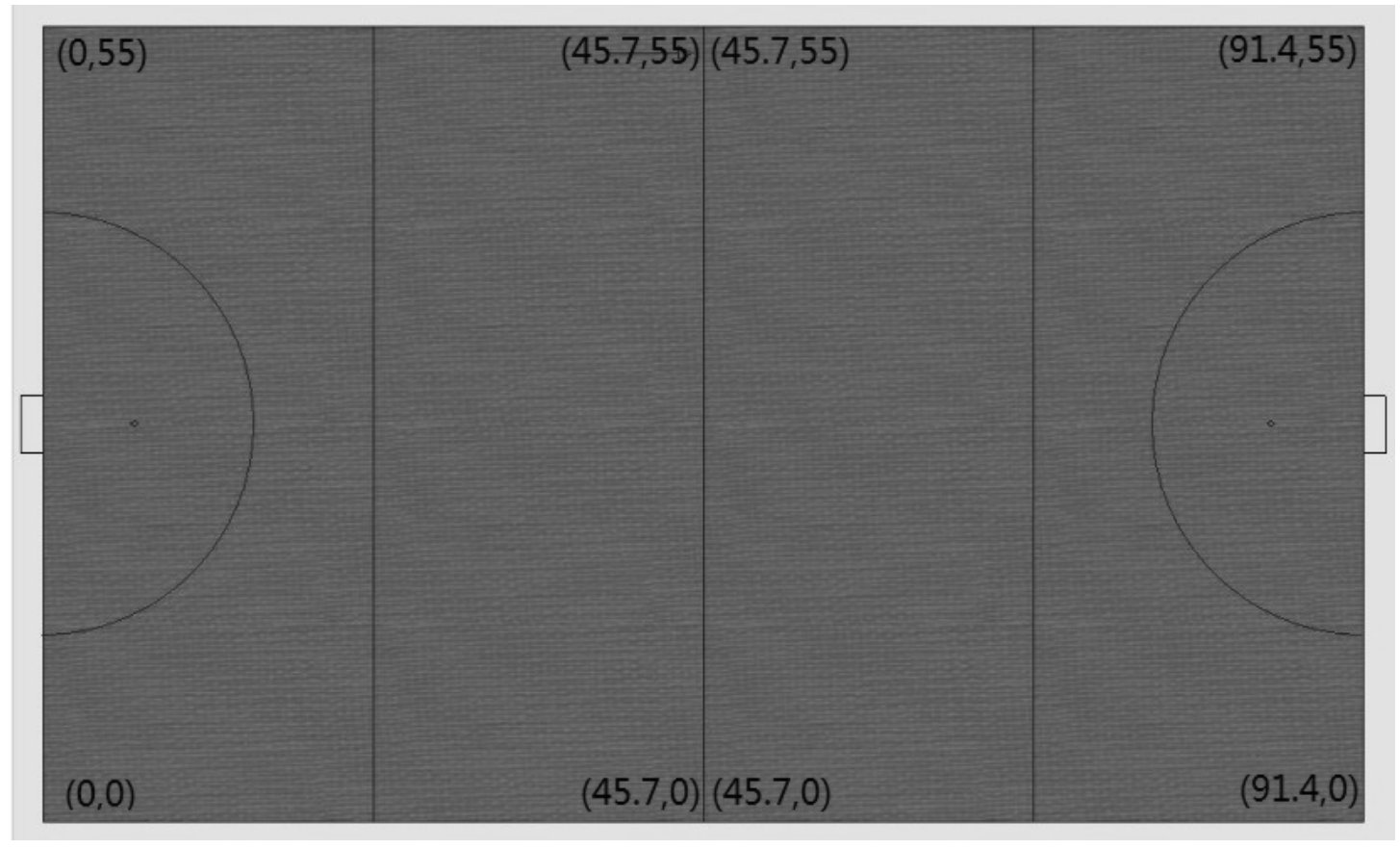

Figure 1. Two dimensional coordinate of the hockey pitch in video in SIMI Scout system

With the coordinate $\left(\mathrm{X}_{\mathrm{i}}, \mathrm{Y}_{\mathrm{i}}\right)$ and time (i) of a player in video, his distance $\left(\mathrm{D}_{\mathrm{i}}\right)$ moved from time " $i-1$ " to "i" could be calculated using formula (1) in Excel (Ai, Wang, Liu and Zhao, 2005):

$$
D_{i}=v\left[\left(X_{i}-X_{i-1}\right)^{2}+\left(Y_{i}-Y_{i-1}\right)^{2}\right], i=1,2,3 \ldots
$$


The total distance $\left(D_{t}\right)$ could be calculated using formula (2):

$$
\mathrm{D}_{\mathrm{t}}=\sum \mathrm{D}_{\mathrm{i}}, \mathrm{i}=1,2,3 \ldots
$$

The velocity $\left(\mathrm{V}_{\mathrm{i}}\right)$ from "i-1" to " $\mathrm{i}$ " could be calculated using formula (3):

$$
\mathrm{V}_{\mathrm{i}}=\mathrm{D}_{\mathrm{i}} /[\mathrm{i}-(\mathrm{i}-1)], \mathrm{i}=1,2,3 \ldots
$$

The sample only included players that played in their customary position and that completed the entire match (i.e., $70 \mathrm{~min}$ ). Altogether, statistics of 38 players (Age: 28.8 \pm 3.9 years, Height: $175 \pm 5 \mathrm{~cm}$, Body Mass: $72.1 \pm 6.3 \mathrm{~kg}$ ) were collected.

\subsection{Reliability of data}

All the videos were analyzed by two experienced operators who majored in sport training and had a three-year experience in data gathering with SIMI Scout system at the China Institute of Sport Science. An inter-operator reliability test was carried out before the analysis. The aforementioned two operators were independently requested to digitize the same sequence of a film (built with 2500 frames belonging to different matches) using SIMI Scout system. There were no differences $(\mathrm{P}<0.05)$ between the positions (coordinates: $\mathrm{x}, \mathrm{y}$ ) digitized by the two observers. For inter and intra-rater reliability, the results of Intra-class Correlation Coefficient showed coefficients of agreement of $\mathrm{ICC}=0.98$.

\subsection{Variables}

The dependent variable, the distance covered in meters $(\mathrm{m})$ at different intensities, was used to describe the positional performance. According to Ai (2005) and Liu (2012), the running intensity was classified into six categories: sprinting $\left(\geq 8.2 \mathrm{~m} \cdot \mathrm{s}^{-1}\right)$, high-speed running $\left(\geq 5.7 \mathrm{~m} \cdot \mathrm{s}^{-1},<8.2 \mathrm{~m} \cdot \mathrm{s}^{-1}\right)$, moderate-speed running $\left(\geq 4.3 \mathrm{~m} \cdot \mathrm{s}^{-1},<5.7 \mathrm{~m} \cdot \mathrm{s}^{-1}\right)$, low-speed running $\left(\geq 3.2 \mathrm{~m} \cdot \mathrm{s}^{-1},<4.3 \mathrm{~m} \cdot \mathrm{s}^{-1}\right)$, jogging $\left(\geq 2.1 \mathrm{~m} \cdot \mathrm{s}^{-1},<3.2 \mathrm{~m} \cdot \mathrm{s}^{-1}\right)$, and walking $\left(<2.1 \mathrm{~m} \cdot \mathrm{s}^{-1}\right)$.

The following independent variables were analyzed as well:

1. The playing positions: the 38 players were classified into three groups: defender $(N=14)$, midfielder $(N=11)$ and forward $(N=13)$. (Macutkiewicz and Sunderland, 2011; Jennings et al., 2012; Liu, 2012)

2. The match periods: in order to control for within match activities, the data was collected for first and second half of each match separately. 


\subsection{Statistical Analysis}

To verify the objectives and hypothesis of the study, a repeated measures analysis of variance (ANOVA) was performed for distances covered at different intensities (sprinting, high-speed running, moderate-speed running, low-speed running, jogging and walking) during the first and second half of games for each player from different playing positions (defender, midfielder, and forward). Total distances covered by each player during the first and second half were compared using a paired t-test. Total distances covered by players from different positions were compared using a one-way analysis of variance (ANOVA). The Scheffé test was carried out where it was necessary to establish comparisons between groups. Similarly, the sizes of the impact were calculated using the eta squared $\left(\eta^{2}\right)$. Effect sizes (ES) were calculated and their interpretation was based on the following criteria: $0-0.1=$ weak, $0.1-0.3=$ modest, 0.3-0.5 = moderate, $>0.5=$ strong (Bliese and Halverson, 1998). To analyze the data, the statistical package SPSS 18.0 was used and a significance level was set to $p<.05$. Descriptive results are presented as means \pm standard deviations (distances covered and \% of total distance covered).

\section{Results}

Results showed that during the field hockey matches of the 11th Chinese National Games the players covered an average distance of $7334 \pm 877 \mathrm{~m}$ (ranged from 5390 to 8703 ) over the course of whole match (see Table 1). A percentage of $91.7 \%$ of this distance was covered at low and medium intensity $\left(<5.7 \mathrm{~m} \cdot \mathrm{s}^{-1}\right)$, including moderate-speed running $\left(4.3-5.7 \mathrm{~m} \cdot \mathrm{s}^{-1}, 13.6 \%, 1013 \mathrm{~m}\right)$, low-speed running $(3.2-4.3$ $\left.\mathrm{m} \cdot \mathrm{s}^{-1}, 19.3 \%, 1434 \mathrm{~m}\right)$, jogging $\left(2.1-3.2 \mathrm{~m} \cdot \mathrm{s}^{-1}, 23.1 \%, 1683 \mathrm{~m}\right)$ and walking $\left(<2.1 \mathrm{~m} \cdot \mathrm{s}^{-1}\right.$, $35.7 \%, 2580 \mathrm{~m})$, while only $8.3 \%$ of the total distance was at high intensity $\left(\geq 5.7 \mathrm{~m} \cdot \mathrm{s}^{-1}\right)$. On the other hand, results of paired t-test for match periods showed that players covered less distance $\left(t_{37}=7.95, p<0.001\right)$ in the second half $(3640 \pm 437 \mathrm{~m})$ comparing to the first $(3693 \pm 441 \mathrm{~m})$.

Table 1.Distance covered and percent of total distance (\%TD) at different intensities during entire match

\begin{tabular}{llllllll}
\hline & Sprinting & HSR & MSR & LSR & Jogging & Walking & Total \\
\hline Distance $(\mathrm{m})$ & $53 \pm 23$ & $560 \pm 126$ & $1013 \pm 241$ & $1434 \pm 321$ & $1693 \pm 243$ & $2580 \pm 261$ & $7334 \pm 877$ \\
$\% \mathrm{TD}$ & $0.7 \pm 0.3$ & $7.6 \pm 1.0$ & $13.6 \pm 2.0$ & $19.3 \pm 2.62$ & $23.1 \pm 1.6$ & $35.7 \pm 5.8$ & 100 \\
\hline
\end{tabular}

$\mathrm{HSR}=$ high-speed running; MSR = moderate-speed running; LSR = low-speed running.

Results of the one way analysis of variance for total distance covered by players of different positions $\left(F_{2,35}=9.07 ; p<0.01 ; E S=0.34\right)$ showed that the midfield players $(p=0.003)$ and forwards $(p=0.004)$ covered significantly greater distance than defenders (see Table 2). No significance was found between the distance covered by forwards and 
midfielders $(p>0.05)$.

Table 2. Distance covered depending on players' position during entire match.

\begin{tabular}{llll}
\hline & Mean \pm s.d. & Maximum & Minimum \\
\hline Forward & $7709 \pm 720^{*}$ & 8491 & 5970 \\
Midfielder & $7733 \pm 729^{*}$ & 8703 & 6019 \\
Defender & $6671 \pm 745^{+\#}$ & 7492 & 5390 \\
Independent of Position & $7334 \pm 877$ & 8703 & 5390 \\
\hline
\end{tabular}

* significantly different from Defender; ${ }^{*}$ significantly different from Midfielder; ${ }^{+}$significantly different from Forward

The descriptive results of distance covered at different intensities by players from each playing position according to the match period are shown in Table 3.

Table 4 presents the results of main effects and interactions (repeated measures ANOVA) of distance covered by players from different positions at different intensities (sprinting, high-speed running, moderate-speed running, low-speed running, jogging and walking) during the first and second half. As can be seen, significant differences were found between two halves in the distance covered at the speed zones of sprinting $\left(F_{2,35}=64.84\right.$; $p<0.01 ; \quad E S=0.65)$, high-speed running $\left(F_{2,35}=84.73 ; \quad p<0.01 ; \quad E S=0.71\right)$, moderate-speed running $\left(F_{2,35}=125.6 ; \quad p<0.01 ; \quad E S=0.78\right)$, low-speed running $\left(F_{2,35}=168.6 ; p<0.01 ; E S=0.83\right)$, and jogging $\left(F_{2,35}=10.41 ; p<0.01 ; E S=0.23\right)$, but no significance found at the walking intensity. Meanwhile, according to the players' positions, significant differences were found among all the speed zones: sprinting $\left(F_{2,35}=15.04 ; p<0.01 ; E S=0.46\right)$, high-speed running $\left(F_{2,35}=4.71 ; p<0.05 ; E S=0.21\right)$, moderate-speed running $\left(F_{2,35}=11.85 ; \quad p<0.01 ; E S=0.40\right)$, low-speed running $\left(F_{2,35}=16.33 ; p<0.01 ; E S=0.48\right)$, jogging $\left(F_{2,35}=17.09 ; p<0.01 ; E S=0.49\right)$ and walking $\left(F_{2,35}=4.18 ; p<0.05 ; E S=0.20\right)$. Finally, the interaction between match period and playing position determines the distances of sprinting $\left(F_{2,35}=75.87 ; p<0.01 ; E S=0.84\right)$ and moderate-speed running $\left(F_{2,35}=12.29 ; p<0.01 ; E S=0.41\right)$. 
Table 3. Distance covered and percent of total distance covered (\%TD) at different intensities of both halves depending on players' position

\begin{tabular}{|c|c|c|c|c|c|c|c|c|c|}
\hline Position & Period & Distance & Sprinting & HSR & MSR & LSR & Jogging & Walking & Total \\
\hline \multirow{4}{*}{ Forward } & \multirow{2}{*}{ First Half } & Distance(m) & $42 \pm 12$ & $308 \pm 57$ & $558 \pm 94$ & $801 \pm 111$ & $889 \pm 94$ & $1286 \pm 106$ & $3884 \pm 372$ \\
\hline & & $\% \mathrm{TD}$ & $1.1 \pm 0.2$ & $7.9 \pm 0.8$ & $14.3 \pm 1.4$ & $20.6 \pm 1.7$ & $22.9 \pm 1.0$ & $33.4 \pm 4.2$ & 100 \\
\hline & \multirow{2}{*}{ Second Half } & Distance(m) & $31 \pm 11$ & $294 \pm 55$ & $552 \pm 97$ & $782 \pm 118$ & $885 \pm 92$ & $1281 \pm 89$ & $3825 \pm 349$ \\
\hline & & $\% \mathrm{TD}$ & $0.8 \pm 0.2$ & $7.6 \pm 0.8$ & $14.3 \pm 1.5$ & $20.4 \pm 2.0$ & $23.1 \pm 1.0$ & $33.8 \pm 4.6$ & 100 \\
\hline \multirow{4}{*}{ Midfielder } & \multirow{2}{*}{ First Half } & Distance $(m)$ & $26 \pm 9$ & $313 \pm 63$ & $582 \pm 97$ & $822 \pm 146$ & $942 \pm 113$ & $1205 \pm 94$ & $3889 \pm 366$ \\
\hline & & $\% \mathrm{TD}$ & $0.7 \pm 0.2$ & $8.0 \pm 1.0$ & $14.9 \pm 1.3$ & $21.0 \pm 2.6$ & $24.2 \pm 1.0$ & $31.4 \pm 5.0$ & 100 \\
\hline & \multirow{2}{*}{ Second Half } & Distance(m) & $25 \pm 8$ & $295 \pm 63$ & $567 \pm 98$ & $801 \pm 145$ & $930 \pm 112$ & $1225 \pm 94$ & $3843 \pm 363$ \\
\hline & & $\% \mathrm{TD}$ & $0.6 \pm 0.2$ & $7.6 \pm 1.0$ & $14.6 \pm 1.4$ & $20.7 \pm 2.6$ & $24.1 \pm 1.1$ & $32.2 \pm 5.1$ & 100 \\
\hline \multirow{4}{*}{ Defender } & \multirow{2}{*}{ First Half } & Distance(m) & $17 \pm 7$ & $254 \pm 59$ & $418 \pm 94$ & $583 \pm 97$ & $740 \pm 60$ & $1349 \pm 150$ & $3362 \pm 368$ \\
\hline & & $\% \mathrm{TD}$ & $0.5 \pm 0.2$ & $7.5 \pm 1.2$ & $12.3 \pm 2.0$ & $17.3 \pm 1.6$ & $22.1 \pm 1.8$ & $40.3 \pm 3.5$ & 100 \\
\hline & \multirow{2}{*}{ Second Half } & Distance(m) & $19 \pm 6$ & $232 \pm 50$ & $398 \pm 95$ & $563 \pm 99$ & $738 \pm 62$ & $1360 \pm 162$ & $3309 \pm 378$ \\
\hline & & $\% \mathrm{TD}$ & $0.6 \pm 0.2$ & $6.9 \pm 1.0$ & $11.9 \pm 2.1$ & $16.9 \pm 1.7$ & $22.4 \pm 2.0$ & $41.2 \pm 3.7$ & 100 \\
\hline
\end{tabular}

$\mathrm{HSR}=$ high-speed running; MSR= moderate-speed running; $\mathrm{LSR}=$ low-speed running.

The post-hoc comparisons for match period showed that players covered a less distance at the second half comparing to the first at all intensities except walking which showed no difference $(p=0.22)$. While the comparisons of playing position differences showed that forwards covered more distance than defenders at the intensity of sprinting ( $p=0.001)$, high-speed running $(p=0.04)$, moderate-speed running $(p=0.001)$, low-speed running ( $p=0.001)$, jogging $(p=0.001)$, and also covered greater distance at the speed zone of sprinting than midfielders $(p=0.002)$. Furthermore, midfielders covered more distance than defenders at the speed zones of high-speed running $(p=0.004)$, moderate-speed running $(p=0.001)$, low-speed running $(p=0.001)$ and jogging $(p=0.001)$. However, conversely the defenders covered more distance than midfielders at the intensity of walking $(p=0.02)$. Meanwhile, the interaction of the match period and playing position factors showed higher values in sprinting during the first half compared to the second for forwards $(p<0.01)$, and in moderate-speed running for defenders $(p=0.0001)$. 
Table 4. Results of repeated-measures ANOVA for the effects and interactions of distance covered at each intensity according to players' position during first and second half

\begin{tabular}{|c|c|c|c|c|c|c|}
\hline & Sum of Squares & DF & Squared average & $\mathrm{F}$ & $\mathrm{p}$ & $\eta^{2}$ \\
\hline \multicolumn{7}{|l|}{ Sprinting } \\
\hline Match period & 230.485 & 1 & 230.485 & 64.84 & $.001 * *$ & .65 \\
\hline Position & 4649.78 & 2 & 2324.89 & 15.04 & $.001 * *$ & .46 \\
\hline Match period x Position & 539.335 & 2 & 269.66 & 75.87 & $.000 *$ & .84 \\
\hline \multicolumn{7}{|l|}{ HSR } \\
\hline Match period & 6152.42 & 1 & 6152.42 & 84.73 & $.001 * *$ & .71 \\
\hline Position & 62330.1 & 2 & 31165.01 & 4.71 & $.015^{*}$ & .21 \\
\hline Match period x Position & 211.94 & 2 & 105.97 & 1.45 & .246 & - \\
\hline \multicolumn{7}{|l|}{ MSR } \\
\hline Match period & 3320.79 & 1 & 3320.79 & 125.6 & $.001 * *$ & .78 \\
\hline Position & 433074.8 & 2 & 216537.4 & 11.85 & $.001 * *$ & .40 \\
\hline Match period x Position & 649.98 & 2 & 324.99 & 12.29 & $.001 * *$ & .41 \\
\hline \multicolumn{7}{|l|}{ LSR } \\
\hline Match period & 7446.70 & 1 & 7446.70 & 168.6 & $.001 * *$ & .83 \\
\hline Position & 921575.11 & 2 & 4060787.55 & 16.33 & $.001^{* *}$ & .48 \\
\hline Match period x Position & 17.75 & 2 & 8.87 & 0.20 & .819 & - \\
\hline \multicolumn{7}{|l|}{ Jogging } \\
\hline Match period & 755.16 & 1 & 755.16 & 10.41 & $.003 * *$ & .23 \\
\hline Position & 541946.1 & 2 & 270973.05 & 17.09 & $.001 * *$ & .49 \\
\hline Match period x Position & 245.79 & 2 & 122.89 & 1.694 & .198 & - \\
\hline \multicolumn{7}{|l|}{ Walking } \\
\hline Match period & 1222.06 & 1 & 1222.06 & 1.57 & .218 & - \\
\hline Position & 2421.33 & 2 & 121066.63 & 4.18 & $.024 *$ & .20 \\
\hline Match period x Position & 1936.242 & 2 & 968.21 & 1.24 & .301 & - \\
\hline
\end{tabular}

$* p<0.05 ; * * p<0.01 ; \mathrm{HSR}=$ high-speed running; $\mathrm{MSR}=$ moderate-speed running; $\mathrm{LSR}=$ low-speed running.

\section{Discussion}

The present study aimed to assess the match performance and physiological demands of individualized Chinese field hockey players who played the 70 min of matches in the same position by determine the distance covered at different intensities (i.e., sprint, high speed running, moderate-speed running, low-speed running, jogging and walking) pooled by specific positions in match. It was hypothesized that the individual player's match performance in field hockey is differed by the playing position and also by the match period (i.e., first and second half). 


\subsection{Overall characteristics}

Current study found that Chinese field hockey players who played one position during entire match cover $7334 \mathrm{~m}$ (ranged from 5390 to 8703) on average, which is more than the mean distance covered by female players (Gabbett, 2010; Macutkiewicz and Sunderland, 2011) but less than elite international tournament players (Lythe and Kilding, 2011; Jennings et al., 2012). The finding that $8.3 \%$ of the total distance was covered at high intensities (sprinting and high-speed running) was greater than most of the previous studies (Boddington, 2002; Spencer et al., 2004; Spencer et al., 2005; Gabbett, 2010; Macutkiewicz and Sunderland, 2011; Lythe and Kilding, 2011), but lower than Macleod et al. (2007) and Jennings et al. (2012). The differences may be generated from the research technologies (i.e. video analysis and GPS technology) and speed categorizations employed.

Former studies (Boddington, 2002; Spencer et al., 2004; MacLeod et al., 2007; Lythe and Kilding, 2011) had already observed differences between match activities during first and second half, but only significances of specific intensities were detected, and what is more is that sometimes contradictory finding was established. Jennings et al. (2012) attributed this kind of differences to the data-collection methods used in these time-motion-analysis studies. However, authors of current research tend to believe that this is because the variability of the sample selected. The present research chose only the players who played entire match which made the comparison between halves more reliable. We found that both players' total distances covered and distances covered at all the speed zones except walking exit significant differences between first and second half of match which confirm the research hypothesis. This result indicates the fact that the fatigue accumulates with the procedures of matches, and coaches need to pay attention to this situation and take out training and match plans accordingly.

\subsection{Positional differences}

In agreement with previous studies (Boddington, 2002; Spencer et al., 2005; Gabbett, 2010; Lythe and Kilding, 2011; Macutkiewicz and Sunderland, 2011), and accord with our research hypothesis, there are positional differences exiting in both the players' total distances covered and distances at various speed zones. Midfielders and forwards covered significantly greater distance than defenders at total distance and at intensities of high-speed running, moderate-speed running, low-speed running and jogging. While comparing to midfielders and forwards, defenders spent more distance on walking. Forwards sprinted the most among all three positions. These findings verified that specific tactic and strategy demands of different positions call for individualized physiological requirements which should finally emphasized the importance of conditioning programs during training.

An exclusive finding of current research is that comparing to their counterparts from other positions, forwards were detected a sharp decrease at the intensity of sprinting during the second half of match, and also a slight decrease in the moderate-speed 
running distance of defenders. This fact suggests that the coaches should make appropriate substitutions in the position of strikers and the forward players should specifically strengthen their endurance of sprinting to keep up with the match demands. Meanwhile, the defenders should keep on sufficient moderate intensity physical training.

\section{Limitations}

Former studies (Spencer et al., 2004; Spencer et al., 2005; Gabbett, 2010; Macutkiewicz and Sunderland, 2011; Lythe and Kilding, 2011; Jennings et al., 2012) showed a high interest in the time and frequencies of players' match movements which are not included in the present research. Further studies of this kind should add these two aspects.

\section{Conclusion}

In conclusion, the individualized analysis by playing position of the demands of match-play in field hockey may be used to prepare and design training programs that take into account the needs of field hockey players, thereby avoiding the periods of fatigue due to over-training or due to an incorrect scheduling of the volume and intensity in the training loads. As a result, reduced field hockey tasks could be designed (i.e. small-side games) that are able to reproduce the demands of match-play taking into account the individual needs of each player, not simply depending on their specific position, but also their physiological performance profile.

\section{Acknowledgements}

The first author is funded by the Chinese Scholarship Council (CSC). Additionally, the authors would like to thank Professor Liu Dan of China Institute of Sport Science who made the statistics available. Meanwhile, the reviews and comments on the improvement of the study from Dr. Peter O’Donoghue are highly appreciated.

\section{Reference}

AiK.W., Wang X.L., Liu D. and Zhao G. (2005).

Zuqiuyundongyuanbisaitiaojianxiayundongjuliceliangheyundongsudufenxi.

[Movement Distance Measurement and Speed Analysis of Players in Soccer Match].China Sport Science and Technology. 41, 81-84.

Bangsbo J, Norregaard L andThorso F. (1991).Activity profile of competition 
soccer.Canadian Journal of Sport Sciences. 16, 110-116.

Barros R.M.L., Misuta M.S., Menezes R.P., Figueroa P.J., Moura F.A., Cunha S.A., Anido R. andLeite N.J. (2007). Analysis of the distances covered by first division Brazilian soccer players obtained with an automatic tracking method. Journal of Sports Science and Medicine. 6, 233-242.

Bliese P.D. and Halverson R.R. (1998).Group Size and Measures of Group-Level Properties: An Examination of Eta-Squared and ICC Values.Journal of Management.24, 157-172.

Boddington M. K., Lambert M. I., Gibson A.S.C. and Noakes T.D. (2002).A time-motion study of female field hockey players.Journal of Human Movement Studies. 43, 229-249.

Castagna C., D' Ottavio S., Abt G. (2003).Activity profile of young soccer players during actual match play.Journal of Strength and Conditioning Research. 17, 775-780.

Di Salvo V., Baron R., Tschan H., Montero F. J. C., Bachl N. andPigozzi F. (2007). Performance Characteristics According to Playing Position in Elite Soccer.International Journal of Sports Medicine. 28, 222-227.

Elzbieta H., Piotr U. and Peter O. (2008). Reliability of a computerised system for recording location on a tenniscourt.International Journal of Performance Analysis in Sport.8, 138-144.

Gabbett T.J. (2010).GPS analysis of elite women's field hockey training andcompetition.Journal of Strength and Conditioning Research. 24, 1321-1324.

Jennings D.,Cormack S.J., Coutts A.J. andAughey R.J. (2012).GPS Analysis of an International Field Hockey Tournament.International journal of Sports Physiology and Performance. 7, 224-231.

Liu H.Y. (2012). Woguoyouxiunanziqugunqiuyundongyunbisaifuhetezhengfenxi. [Analysis on the Match Physical Load Characteristics of Chinese Elite Male Field Hockey Players] (Unpublished Master's Thesis).Shenzhen University, Shenzhen. China.

LytheJ. and Kilding A.E., (2011).Physical Demands and Physiological Responses during Elite Field Hockey.International Journal of Sports Medicine. 32, 523-528.

Macleod H., Bussell C., Sunderland C. (2007).Time-motion analysis of elite women's field hockey, with particular reference to maximum intensity movement patterns.International Journal of Performance Analysis in Sport. 7, 1-12.

Macutkiewicz D. and Sunderland C., (2011). The use of GPS to evaluate activity profiles of elite women hockey players during match-play. Journal of Sports Sciences. 29, 967-973.

Mayhew S.R., Wenger H.A. (1985). Time-motion analysis of professional soccer.Journal of Human Movement Studies. 11, 49-52.

O'Donoghue P. (2007). Reliability Issues in Performance Analysis.International Journal of Performance Analysis in Sport.7, 35-48. 
Podgórski T. andPawlak M. (2011). A Half Century of Scientific Research in Field Hockey. Human Movement. 12, 108-123.

Reilly T. (2001). Assessment of sports performance with particular reference to field games.European Journal of Sport Science. 1, 1-12.

Reilly T., Thomas V. (1976).A motion analysis of work rate in different positional roles in professional football match play.Journal of Human Movement Studies. 2, 87-97.

Spencer M., Lawrence S., Rechichi C., Bishop D., Dawson B. and Goodman C. (2004).Time-motion analysis of elite field hockey, with special reference to repeated-sprint activity.Journal of Sports Sciences. 22, 843-850.

Spencer M., Rechichi C., Lawrence S., Dawson B., Bishop D., Goodman C. (2005).Time-motion analysis of elite field hockey during several games in succession.a tournament scenario.Journal of Science and Medicine in Sport.8, 382-391.

Stroyer J., Hansen L., Klausen K. (2004). Physiological profile and activity pattern of young soccer players during match play. Medicine and Science in Sports and Exercise. 36, 168-174. 